\title{
Crown Ratio Models for Tectona grandis (Linn. f) Stands in Osho Forest Reserve, Oyo State, Nigeria
}

\author{
Popoola F.S. ${ }^{1}$ and Adesoye P.O.,* \\ ${ }^{1}$ Department of Forestry $\mathcal{E}^{2}$ Wildlife, University of Portharcout, Portharcout, Nigeria \\ ${ }^{2}$ Department of Forest Resources Management, University of Ibadan, Oyo, Nigeria
}

\begin{abstract}
Crown ratio is the ratio of live crown length to tree height. It is often used as an important predictor variable for tree growth equation. It indicates tree vigor and is a useful parameter in forest health assessment. The objective of the study was to develop crown ratio prediction models for Tectona grandis. Based on the data set from the temporary sample plots, several non linear equations including logistics, Chapman Richard and exponential functions were tested. These functions were evaluated in terms of coefficient of determination $\left(\mathrm{R}^{2}\right)$ and standard error of the estimate (SEE). The significance of the estimated parameters was also verified. Plot of residuals against estimated crown ratios were observed. Although the logistic model had the highest $\mathrm{R}^{2}$ and the least SEE, Chapman-Richard and Exponential functions were observed to be more consistent in their predictive ability; and were therefore recommended for predicting crown ratio in the stand.
\end{abstract}

Key Words: crown ratio, tree growth variables, modeling, Tectona grandis

\section{Introduction}

Tree crown is one complement of net primary production and its dimensions reflect general tree health. Dense and large crowns are associated with potential growth rates. Sparse and small crowns can prove responsive to unfavourable site conditions (competition, moisture, diseases) (Kozlowski et al. 1991). Tree crown research contributes to several key forest ecosystem attributes: biodiversity, productivity, forest management, forest environment, and wildlife (Laar and Akca 1997; Avery and Burkhart 2001). The crown displays the leaves to allow the capture of radiant energy for photosynthesis. Thus, measurement of a tree crown is often used to assist in the quantification of tree growth (Kozlowski et al. 1991). The size of a tree crown has a marked effect on and is strongly correlated with the growth of the tree and its various parts (Temesgen et al. 2005).

Crown ratio (CR), which is the ratio of live crown length to the total height of the tree, is widely used to predict growth and yield of trees and forests (Wykoff et al. 1982; Sprinz and Burkhart 1987). CR is a useful indicator of tree vigor (Hasenauer and Monserud 1996), wood quality (Kershaw et al. 1990), wind firmness (Navaratil 1997), stand density (Clutter et al. 1983) and is a feature of interest in management of many non-timber resources including wildlife habitat and recreation (Mcgaughey 1997). Predictions of tree crown ratio have been based on allo-

Received: September 14, 2011. Revised: February 12, 2012. Accepted: February 16, 2012.

Corresponding author: Adesoye P.O.

Department of Forest Resources Management, University of Ibadan, Oyo, Nigeria

Tel: 234-80-63311799, Fax: 234-2-810-3043, E-mail: adesoyepet@yahoo.com 
metric relationship between stand and tree variables. Many authors have based crown ratio equation on logistic functions (Hasenauer and Monserud 1996; Temesgen et al. 2005 ) or the exponential function (Holdaway 1986; Dyer and Burhart 1987) or chapman richard function (Soares and Tome 2007; Adesoye and Oluwadare 2008). Most of these models were formulated for either even aged single species stands, or multi-species stands comprising of different ages or mixed stand with two or more species. The objective of this study is to develop crown ratio prediction model for Tectona grandis stand in Osho forest reserve.

\section{Materials and Methods}

\section{Study area}

Osho forest reserve is located in the derived savanna ecological zone of Nigeria. It is situated in Ido local government area of Oyo state, Nigeria between latitudes $6^{\circ} 50^{\prime}$ and $7^{\circ} 30^{\prime} \mathrm{N}$ and longitudes $3^{\circ} 30^{\prime}$ and $4^{\circ} 30^{\prime} \mathrm{E}$. The reserve has an estimated altitude of $152 \mathrm{~m}$ above the sea level.

\section{The data}

Data used for this study was collected from twenty seven (27) randomly selected temporary sample plots of size $20 \times$ $20 \mathrm{~m}$ within the study area. Within each sample plot, the following tree growth variables were measured for all trees: total height $(\mathrm{m})$, bole height $(\mathrm{m})$, merchantable height $(\mathrm{m})$, crown length $(\mathrm{m})$, diameter $(\mathrm{cm})$ outside bark at breast height (i.e. dbh measured at $1.3 \mathrm{~m}$ above the ground level), diameter $(\mathrm{cm})$ outside bark at top, middle and base, crown diameter $(\mathrm{cm})$.

\section{Model description and fitting procedure}

The tree crown ratio models developed and tested for this study were the Logistic, Chapman-Richard and Exponential models since a crown ratio value ranges from 0 (i.e. no crown, dead or defoliated) to 1 (i.e. crown extends over the entire tree bole). The tree crown ratio model formulated to express crown ratio as a function of tree size (e.g. basal area, merchantable height) and slenderness coefficient. The original forms of the models are:

$$
C R=\left[1-e^{-\beta X}\right]^{-1}
$$

$$
\begin{aligned}
& C R=\frac{1}{\left[1+e^{-\beta X}\right]^{\frac{1}{2}}} \\
& C R=b_{0}+e^{-\beta X}
\end{aligned}
$$

Where, $\mathrm{CR}$ is estimated crown ratio, $\beta \mathrm{x}$ is linear equation with parameter $\beta$ and independent variable $\mathrm{x}$ (which includes individual tree characteristics such as merchantable height-MHT, Diameter at breast height-D and Tree Slenderness Coefficient-TSC) and e is Naperian constant. The multiple linear regression equation for the independent variables was given as follows:

$$
\beta x=\beta_{0}+b x_{1}+c x_{2}+d x_{3}
$$

Where, $\beta_{0}$ is intercept, $\mathrm{b}$ to $\mathrm{d}$ is set of parameters, $x_{1}$ to $x_{3}$ is the independent variables.

Equation 4 was fitted to the data obtained from the study. This was then inserted into equation 1,2 and 3 respectively for estimation of the parameters.

$$
C R=\left[1-e^{-\beta_{0}+b x_{1}+c x_{2}+d x_{3}}\right]^{-1}
$$

For example, eqution 4 was inserted into equation 4 to obtain equation 5; and was fitted to the data. Model development was done at the individual tree level (i.e. mean values of tree growth variables for each plot).

\section{Computation of derived variables}

The following variables were derived from the tree growth data collected:

(i) Stem basal area computed as

$$
B A=\frac{\pi D^{2}}{4}
$$

Where, $\mathrm{BA}=$ Stem basal area $\left(\mathrm{m}^{2}\right)$ $\mathrm{D}=$ Diameter at breast height $(\mathrm{m})$

(ii) Tree Slenderness coefficient computed as

$$
T S C=\frac{T H T}{D}
$$

Where, $\mathrm{TSC}=$ Tree slenderness coefficient THT $=$ Tree total height $(\mathrm{m})$ $\mathrm{D}=$ Diameter at breast height $(\mathrm{m})$ 


\section{Model evaluation}

The models formulated were evaluated with a view of selecting the best estimator for tree crown ratio. The evaluation was based on the following criteria:

* Coefficient of determination $\left(\mathrm{R}^{2}\right)$

* Standard error of estimate (SEE)

In addition, the significance of regression coefficients $(t)$ was observed. Only equations having all the parameters to be significant were selected. A model with high $\mathrm{R}^{2}$ and low SEE was judged to have good fit. Residuals values were plotted against the predicted crown ratio values to check the constant error assumption.

\section{Results and Discussion}

\section{Data summary}

The model fitting data set covered a wide range. The mean, maximum and minimum of the main measured vari-

Table 1. Characteristics of the tree variable used for modeling

\begin{tabular}{lccc}
\hline \multicolumn{1}{c}{ Variable } & Mean & Minimum & Maximum \\
\hline DBH $(\mathrm{m})$ & 0.1392 & 0.045 & 0.3072 \\
THT $(\mathrm{m})$ & 8.9752 & 3.12 & 16.35 \\
MTH $(\mathrm{m})$ & 6.8979 & 2.2 & 14.5 \\
CR & 0.45 & 0.03 & 0.75 \\
TSC & 66.3553 & 21.0845 & 221.5226 \\
Dt/Db & 0.3394 & 0.1166 & 2.536 \\
\hline
\end{tabular}

$\mathrm{Dt} / \mathrm{Db}$, Ratio of tree diameter at the top to tree diameter at the base. ables and other derived variables are presented in Table 1 below.

The large range of crown ratio values in each data set reflects the effect of stand density and site productivity. This range variation was also observed by Soares and Tome (2001). In this study effort was directed towards obtaining crown ratio prediction models. Before the models were developed, correlation analysis was carried out to give an insight of the association between crown ratio and the growth variables. It was observed from the correlation matrix presented in Table 2 that crown ratio decreased with increasing tree size and competition. Similar trend was observed by Hasenauer and Monserud (1996), Temesgen et al. (2005).

Generally crown ratios are expected to be longer for lower densities (Clutter et al. 1983; Oliver and Larson 1996). Conversely trees with close neighbours on all sides maintain small crown ratio and eventually slow in diameter growth. The negative correlation of crown ratio with tree slenderness coefficient indicates that trees that are tall and slender had lower crown ratio values.

\section{Model fitting and evaluation}

Model fitting and evaluation are important parts of model building. Fitting of crown ratio models were based on the total data set. A number of different models were examined for predicting crown ratio using logistic, exponential and Chapman Richard functions. In this study coefficient of determination $\left(\mathrm{R}^{2}\right)$ and standard error of estimate (SEE) were computed in order to evaluate the fitted models. In addition, residual plots were carried out to check the error assumption. The significance of the parameter estimates

Table 2. Correlation matrix for individual tree growth variables

\begin{tabular}{|c|c|c|c|c|c|c|c|c|}
\hline & AGE & $\mathrm{DBH}$ & SV & THT & MHT & $\mathrm{BH}$ & $\mathrm{CL}$ & $\mathrm{CR}$ \\
\hline AGE & 1.00 & & & & & & & \\
\hline $\mathrm{DBH}$ & $0.17^{\mathrm{a}}$ & 1.00 & & & & & & \\
\hline SV & $0.17^{\mathrm{a}}$ & $0.82^{\mathrm{a}}$ & 1.00 & & & & & \\
\hline THT & $0.11^{\mathrm{a}}$ & $0.78^{\mathrm{a}}$ & $0.85^{\mathrm{a}}$ & 1.00 & & & & \\
\hline MHT & $0.10^{\mathrm{a}}$ & $0.64^{\mathrm{a}}$ & $0.85^{\mathrm{a}}$ & $0.90^{\mathrm{a}}$ & 1.00 & & & \\
\hline $\mathrm{BH}$ & $0.11^{\mathrm{a}}$ & $0.52^{\mathrm{a}}$ & $0.77^{\mathrm{a}}$ & $0.80^{\mathrm{a}}$ & $0.92^{\mathrm{a}}$ & 1.00 & & \\
\hline $\mathrm{CL}$ & 0.00 & $0.43^{\mathrm{a}}$ & $0.15^{\mathrm{a}}$ & $0.35^{\mathrm{a}}$ & 0.01 & $-0.29^{\mathrm{a}}$ & 1.00 & \\
\hline CR & $-0.06^{\mathrm{a}}$ & 0.02 & $-0.27^{\mathrm{a}}$ & $-0.17^{\mathrm{a}}$ & $-0.45^{\mathrm{a}}$ & $-0.71^{\mathrm{a}}$ & $0.83^{\mathrm{a}}$ & 1.00 \\
\hline
\end{tabular}

AGE, Tree Age (years); DBH, Diameter at breast height (cm); SV- Stem Volume (m3); THT, Tree total height (m); MHT, Merchantable Height (m); BH, Bole height (m); CL, Crown length (m); CR, Tree crown ratio. 
Table 3. Selected tree crown ratio models

\begin{tabular}{llcc}
\hline \multicolumn{1}{c}{ Function } & \multicolumn{1}{c}{ Model } & $\mathrm{R}^{2}$ & $\mathrm{SEE}$ \\
\hline Logistic & $C R=1 /(1+\exp (-0.873+0.111 M H T+0.01 T S C))$ & 0.34 & 0.1328 \\
Chapman-Richard & $C R=-0.591 /\left(1-\exp (1+0.722 M H T+0.007 T S C)^{1 / 2}\right)$ & 0.20 & 0.1355 \\
Exponential & $C R=-0.599+\exp (-0.026 M H T+8.866 / T S C)$ & 0.23 & 0.1355 \\
\hline
\end{tabular}

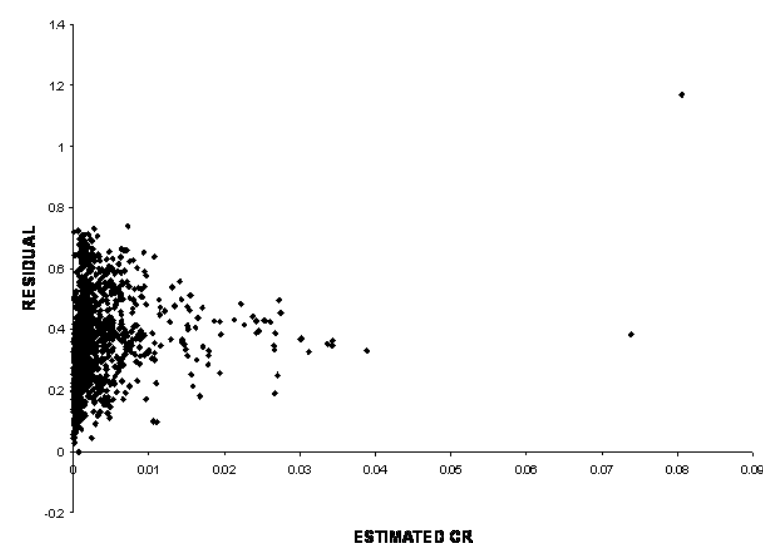

Fig. 1. Relationship between residual and estimated CR using logistic function.

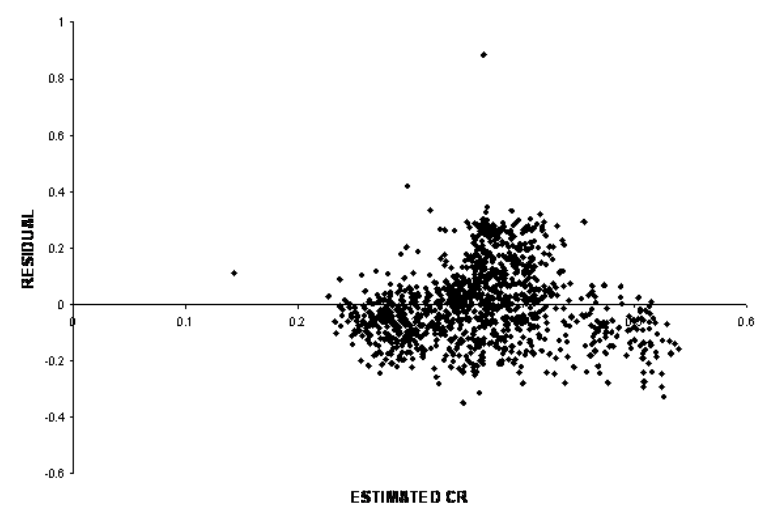

Fig. 2. Relationship between residual and estimated CR using exponential function.

was also observed. The selected versions of the models are presented in Table 3. One unique independent variable that features in all the models is tree slenderness coefficient. This proves that tree slenderness coefficient is one of the factors contributing to the size of tree crown ratio. The pattern was observed in the studies conducted by Hanus et al.

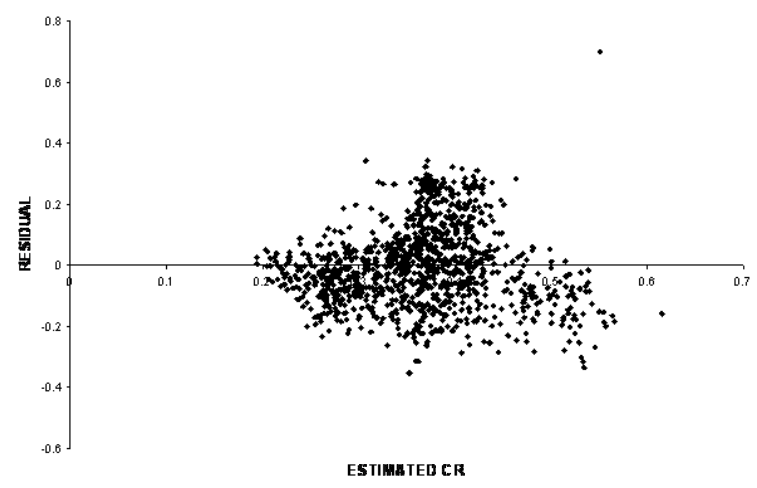

Fig. 3. Relationship between residual and estimated CR under ChapmanRichard function.

(2000); Hasenauer and Monserud (1996); Ritchie and Hann (1987). Merchantable height was another important variable used in modeling. Adesoye and Oluwadare (2008); Marshall et al. (2003) also found merchantable height as an important variable for modeling crown. The other variables failed to adequately explain crown ratio variation and were therefore not included in the models. The SEE differences were small since crown ratio is constrained to the interval of 0 and 1 . This was also noticed in the work carried out by Temesgen et al. (2005) and Adesoye and Oluwadare (2008). Generally, the models consistently gave good fit to the Tectona grandis data in Osho Forest Reserve. The evaluation of the residual plots (Fig. 1-3) revealed that logistic model consistently under-predicted the crown ratio. Its error analysis revealed that error variance is not constant across the predicted crown ratio. Chapman-Richard and Exponential functions were observed to have constant error variance.

In the graphical relationship between the residuals and estimated crown ratio obtained with the logistic, all the residual values are in the positive region which implied that crown ratio values were consistently under predicted. Exponential and Chapman-Richard functions judging 
from their error analysis appeared constant error variance distributed both in the positive and negative region of the $\mathrm{x}$-axis (i.e. the estimated crown ratio values). This is desirable for a good model. This trend was similar to the findings of Soares and Tome (2001); Adesoye and Oluwadare (2008). Based on the evaluation of the error analysis, Chapman-Richard and Exponential functions are recommended for predicting crown ratio in the stand. Although their $\mathrm{R}^{2}$ values were lower compared to the logistics, they are more precise in their predictive ability.

\section{Conclusions}

Based on the evaluation of the models examined in this study, the Chapman-Richard and Exponential functions are recommended as crown ratio models for Tectona grandis stand in Osho Forest Reserve. These functions have tree slenderness coefficient and merchantable height as independent variables. It is note worthy that the age range of data used for modeling was small. As more data become available to cover a wider range of ages, the model can further be investigated through validation.

\section{References}

Adesoye OP, Oluwafemi OA. 2008. Interim Crown Ratio Models for a Mixed Tectona grandis and Gmelina arborea Stand in the University of Ibadan, Nigeria. Research Journal of Forestry 2: 34-42.
Avery T, Burkhart HE. 2001. Forest Measurements. 5th ed. McGraw- hill, New York.

Clutter JL, Fotson JC, Pienaar LV, Brister GH, Bailey RL. 1983. Timber Management: A Quantitative Approach. John Wiley and sons, New York.

Dyer ME, Burkhart HE. 1987. Compatible Crown Ratio and Crown Height models. Canadian Journal of Forest Research 17: 572-574.

Hanus MI, Hann DW, Marshal DD. 2000. Predicting Height to Crown Base for Undamaged and Damaged Trees Southwestern Oregon. Research Contribution 29. Forest Research Laboratory, Oregon state University, Covalllis.

Hasenauer H, Monserud RA. 1996. A Crown Ratio Model for Australia Forest. Forest Ecolog And Management 84: 49-60.

Holdaway M. 1986. Modeling Tree Crown Ratio. Forestry Chronicle Research 29: 621-629.

Kershaw JA, Maguire DA, Hann DW. 1990. Longevity and Duration of Radial Growth in Douglas-fir Branches. Canadian Journal of Forest Research 20: 1690-1695.

Kozlowski T, Kramer P, Pallardy S. 1991. The Physiological Ecology of Woody Plants. Academic Press, New York.

Laar A, Akca A. 1997. Forest Mensuration. Cuvillier Verlag, Gottingen.

Marshall DD, Johnson GP, Hann DW. 2003. Crown Profile Equations for Stand Grown Western Hemlock in Northwestern Oregon. Canadian Journal of Forest Research 33: 2059-2066.

McGaughey RJ. 1997. Visualizing Forest Stand Dynamics Using the Stand Visualization System. Proceedings of the 1997 ACSM/ASPRS Annual Convention and Exposition. April 7-10. Seattle, pp 248-257.

Navratil S. 1997. Wind Damage in Thinned Stands. In Proceedings of a Commercial Thinning Workshop. October 17-18. Whitecourt, pp 29-36. 